Article

\title{
Are Emissions Trading Policies Sustainable? A Study of the Petrochemical Industry in Korea
}

\author{
Yongrok Choi * and Hyoung Seok Lee \\ Global E-Governance Program, Inha University, Inharo100, Nam-gu, Incheon 402-751, Korea; \\ zard2303@naver.com \\ * Correspondence: yrchoi@inha.ac.kr; Tel.: +82-32-860-7760; Fax: +82-32-876-9328 \\ Academic Editor: Pauline Deutz \\ Received: 26 August 2016; Accepted: 27 October 2016; Published: 29 October 2016
}

\begin{abstract}
In 2015, Korea inaugurated an emissions trading scheme (ETS). In this regard, many studies have considered the sustainable performance and efficiency of industries that emit carbon; however, few have examined ETS at company level. This paper focuses on companies' data related to Korean ETS in the petrochemical industry. Based on the non-radial, nonparametric directional distance function (DDF), the paper evaluates the governance factors related to ETS policies and sustainable performance in terms of carbon technical efficiency (CTE), the shadow price of carbon emissions, and Morishima elasticity between the input and undesirable output of carbon emissions. Using a dual model, the paper shows that Korean ETS has huge potential for participating companies to improve CTE. If all companies consider the production possibility frontier, they could potentially improve efficiency by $52.8 \%$. Further, Morishima elasticity shows strong substitutability between capital and energy, implying that green technology investment should bring a higher degree of energy-saving performance. Unfortunately, however, the market price of carbon emissions is far too low compared with its shadow price, suggesting that the Korean government's price-oriented market intervention has resulted in the ETS producing poor sustainable performance. As the title suggests, ETS of Korea is not sustainable at the current stage, but with more efforts on the transition period, all the developing countries should support the governance factors of the ETS in terms of the more effective green investment with easier access to the green technology.
\end{abstract}

Keywords: ETS; emissions trading scheme; carbon technical efficiency; CTE; shadow price; Morishima elasticity of substitution; governance

\section{Introduction}

Since the historic meeting of the United Nations Framework Convention on Climate Change (UNFCCC) in 1994, numerous efforts have been made to find the optimal path toward worldwide sustainable development. At Paris in 2015, the 21st session of the Conference of the Parties (COP) agreed to keep the increase in the global average temperature to below two degrees centigrade above the pre-industrial level. The session also agreed to pursue efforts to limit the temperature increase to 1.5 degrees centigrade above the pre-industrial level. These agreements recognized that temperature-control efforts would significantly reduce the risks and impacts of climate change. In order to achieve the UNFCCC's goals, all 195 member countries are required to make clear and measurable efforts for worldwide sustainable development. As one of the leading countries, Korea has promoted its version of green growth policies since the government hosted the G20 Seoul Summit in 2010. Since then, using one of the most powerful market-oriented frames, the Korean government has prepared and promoted its nationwide emissions trading scheme (ETS). This scheme became regulated in 2015; however, it has caused diverse conflict among politicians, industrial leaders, and even academic experts. Thus, the government has provided a cautious pilot scheme that involves 
a weak and constrained ETS. Emissions trading rights are traded only among regulated companies. Moreover, emissions targets have been initially set at $95 \%$ of the regime. Because of this loose, yet uncomfortable, arrangement among ETS interest groups, it is easy for regulated companies not to invest in the sustainable performance of green productivity and to avoid the extra burden of carbon targets in the short run. Consequently, even though many trials have evaluated the effectiveness of ETS-related policies, it is difficult to measure the performance or efficiency of such policies from a field-oriented company perspective. This paper aims to analyze, from a company perspective, whether the milestone policy of ETS in Korea is successful in terms of decreasing carbon emissions efficiently. Since carbon emissions form most greenhouse gas (GHG) emissions, we evaluate the GHG emissions of companies based on their efforts to decrease ETS targets.

In 2012, total GHG emissions in Korea were 688.3 million tons. This figure represents a 133\% increase compared with the base year of 1990. Carbon dioxide $\left(\mathrm{CO}_{2}\right)$ emissions overall were 593 million equivalent tons, a figure that places Korea as the seventh highest producer of such emissions in the world. Carbon emissions per person were 11.7 tons, which places Korea as the 18th highest producer of carbon emissions per person in the world and places it sixth among Organization for Economic Cooperation and Development (OECD) countries. These rankings imply that many other developing countries are more proactive than Korea; thus, Korea should be more aggressive in its attempts to decrease GHG emissions and carbon dioxide. The Korean government set its own target in November 2009, saying that it would reduce GHG emissions by $30 \%$ from BAU (business as usual) levels by 2020. In the Paris agreement of 2015, the Korean government decided to reduce GHG emissions by $37 \%$ from BAU levels by 2030. In order to achieve this target, the government published an emissions trading master plan (2015-2025) in 2014. It also implemented its ETS nationwide in 2015. Unfortunately, however, in spite of these proactive government efforts, the carbon trading market is regarded as a failure because very few transactions took place in the first year. Many experts blame the unreliable carbon price for this failure. They say that the carbon price is so low that companies with emissions permits are reluctant to sell them. Moreover, regulated companies are uninterested in green technology investment because of the low opportunity costs for such innovation. During most of 2015 , the carbon price barely exceeded US $\$ 10$, resulting in the lack of trading. Thus, it is important to analyze whether this price is appropriate or not for achieving the future sustainable performance of the Korean ETS. This issue is the basic motivation of the current research.

In order to monitor and measure efficient carbon reduction, many researchers have conducted carbon efficiency studies based on the distance function because of its reliable clarity about relative efficiency. Although there are numerous sustainable performance modeling methods, the distance function approach has become popular because it can simultaneously model joint-production technology with eco-friendly desirable and undesirable output. Another benefit of the distance function approach is that compared with other cost functions, it does not require any price-specific functional form that is relatively difficult to obtain. Given the quantity of data for input and output, which are comparatively easy to obtain, various critical environmental production characteristics can be formally analyzed. These include environmental technical efficiency, environmental productivity growth, the shadow prices of pollutants, and intra-factor substitution possibilities [1].

Even if Shepherd distance function provides a basic logical frame for the treatment of multi-input/output analysis [2], it is limited in the sense that it treats desirable and undesirable output proportionately; thus, it overlooks the possibility that it decreases undesirable output without any loss in desirable output. Consequently, most directional function research uses the directional distance function (DDF) introduced by Chambers, Chung, and Färe [3]. According to the literature review of Zhang and Choi [1], more than 100 papers have analyzed energy efficiency and the shadow prices of industrial emissions by using distance function models. Studies that use the DDF method employ either the parametric method [4] or the nonparametric method based on data envelopment analysis (DEA) [3,5]. The former can easily calculate the shadow price but has to compute the theoretic distance function coefficients; the latter does not need to preset functional forms and thus can analyze 
the shadow prices of pollutants in all directions with significant flexible implications. Since it is not easy to accept a specific production possibility curve a priori without significant in-depth analysis on the characteristics of the decision units, this research is based on the DDF_DEA.

Most early research on the DDF is based on a radial model that estimates efficiency proportionately for all output [3]. However, several later studies have reported limitations regarding this radial approach. First, radial measures may overestimate efficiency when slack exists [6]. Second, the radial model has relatively weak discriminating power when ranking entities that require evaluation [7]. Third, a radial efficiency measure cannot provide a single-factor efficiency measure, such as energy efficiency, because the DDF can only give the same rate of inefficiency [8]. Because of these limitations, a number of studies have extended the conventional DDF to a non-radial DDF by considering slacks [6,9-11]. Thus, we employ the non-radial DEA-based DDF to examine the sustainable performance of the eco-friendly policies of Korea's ETS.

Most studies in this field have been conducted in the power plant sector [12-16], the steel and iron sector [17-19], the electricity sector [20-22], and other sectors such as the chemical, cement, and ceramic industries. Nearly all of these sectors emit a great deal of $\mathrm{CO}_{2}$ [23-26]. Although these studies have employed the DDF to measure the performance of environmental policies, to the best of our knowledge no research has yet been conducted using company data related to real ETS trading. Moreover, Korea is the only country in the world to promote a nationwide, and not a regional or localized, ETS frame.

Since Korea is in a transitional stage between a developing and developed economy, this research has insightful implications about a stepwise approach to performance-oriented sustainable development. Moreover, this research has potential practical importance because it is based on a comparison between the shadow price and the price in the real world. Further, it evaluates the sustainability of the unduly cautious ETS policies in Korea. In this paper, the sustainability of ETS policies is analyzed from three perspectives. First, the Korean government's ETS policies are excessively price-oriented; thus, we need to check that the semi-regulated market price of carbon emissions permits is acceptable compared with their shadow prices. If the market price is too low, it may result in low investment in green IT technologies, which is contrary to the government's ultimate goal. Of course, the shadow price of carbon could be unrelated to the market carbon price for one important reason: the carbon allowances are given for free and all firms are allocated $100 \%$ of the allowances they need for at least in the first stage of three years. Under these conditions, it is reasonable for carbon allowances to have a low market value in the first few years of the ETS. Hence, it is hard to argue that the shadow prices reflect what the market price should be. However, the government should narrow this gap between the shadow price and market price as early and effectively as possible, and thus if the government stimulates companies to invest more on green technology, the price gap will be more effectively decreased. According to Oestreich and Tsiakas [27], during the first few years of the scheme, firms that received free carbon emission allowances on average significantly outperformed firms that did not in the European Union Emissions Trading Scheme (EU ETS). Even if this kind of transition trial and errors on the inappropriate carbon market price, however, they found that this kind of carbon premium is present for a specific period that commences about one year before the beginning of Phase I and disappears about one year into Phase II [27]. If this is true, then the Korean government should make this trial and error on the carbon market price as short as possible. In this paper, we will check the feasibility of this carbon premium in terms of the price gap between the shadow price and market price.

Second, in order to boost investment in energy-saving green technologies by ETS member companies, there must be significant elastic substitutability between energy and other input. Third, it is necessary to check whether the potential sustainability of ETS policies is increasing the eco-friendly efficiency of participating companies. If not, such companies have no incentive to exert too much effort in proactively participating in ETS trading.

Thus, the purpose of this paper is to examine these three points regarding the sustainability of governmental policies. In this context, we use the ETS data of participating member companies. 
However, the Korean ETS covers 525 companies from diverse industries. Consequently, since the clarity and credibility of the implications are important in order to check the sustainability of the ETS policies, this research focuses on the petrochemical industry. This industry is the largest in the ETS with 85 companies, which represent $16 \%$ of all ETS members. Thus, based on the arguments regarding an examination of the ETS policies' sustainability, this paper estimates the eco-friendly efficiency of the participating member companies in the major field of the petrochemical industry. It compares the shadow price with the market trading carbon price and considers the potential of green investment in terms of Morishima elasticity between capital and energy.

The rest of this paper is organized as follows: Section 2 presents a methodological framework of the non-radial DDF models with Morishima elasticity and describes the data collection. Section 3 presents the results of the empirical study of the petrochemical industry. Section 4 concludes with some policy implications for sustainable governance.

\section{Methodology}

In this section, the non-radial DDF model is presented. This model shows how to estimate carbon technical efficiency. Moreover, a dual model is introduced to calculate the shadow price of undesirable output. Then, the Morishima elasticity of input is articulated from the ratio of the shadow price.

\subsection{Carbon Technical Efficiency}

In order to introduce the non-radial DDF, the term "environmental production technology" should be defined. Assume that there are $j=1, \ldots, N$ decision-making units (DMUs). These DMUs are petrochemical manufacturing companies in our research. Suppose that each DMU uses input vector $x \in \Re_{+}^{M}$ to produce jointly a good output vector $y \in \Re_{+}^{S}$ and a bad output vector $b \in \Re_{+}^{J}$ Environmental production technology is expressed as

$$
T=\{(x, y, b): x \text { can produce }(y, b)\},
$$

where $T$ is often assumed to satisfy the standard axioms of production theory. Inactivity is always possible, and finite amounts of input can produce only finite amounts of output. In addition, input and desirable output are often assumed to be freely disposable. With regard to regulated environmental technologies, weak disposability must be imposed on $T$ [28]. The weak disposability assumption implies that reducing bad output, such as $\mathrm{CO}_{2}$ emissions, is costly in terms of relative decreases in production. Further, the null-jointness assumption implies that $\mathrm{CO}_{2}$ emissions are unavoidable in production and that the only way to remove $\mathrm{CO}_{2}$ is to stop production. Mathematically, these two assumptions can be expressed as follows:

(1) if $(x, y, b) \in T$ and $0 \leq \theta \leq 1$, then $(x, \theta y, \theta b) \in T$;

(2) if $(x, y, b) \in T$ and $b=0$, then $y=0$.

The DEA piecewise linear production frontier is used to construct environmental production technology. Then, regulated environmental technology $T_{1}$ for $N$ DMUs exhibiting constant returns to scale can be expressed as

$$
\begin{gathered}
T_{1}=\left\{(x, y, b): \sum_{n=1}^{N} z_{n} x_{m n} \leq x_{m}, m=1, \ldots, M,\right. \\
\sum_{n=1}^{N} z_{n} y_{s n} \geq y_{s}, s=1, \ldots, S, \\
\sum_{n=1}^{N} z_{n} b_{j n}=b_{j}, j=1, \ldots, J, \\
\left.z_{n} \geq 0, n=1, \ldots, N\right\} .
\end{gathered}
$$


A formal definition of the non-radial DDF is proposed by Zhou et al. [9] with undesirable output as

$$
\vec{D}(x, y, b ; g)=\sup \left\{\mathbf{w}^{T} \beta:((x, y, b)+g \cdot \operatorname{diag}(\beta)) \in T\right\},
$$

where $\mathbf{w}=\left(w_{m}^{x}, w_{s}^{y}, w_{j}^{b}\right)^{T}$ denotes a normalized weight vector relevant to the amount of input and output, $g=\left(-g_{x}, g_{y},-g_{b}\right)$ is an explicit directional vector, and $\beta=\left(\beta_{m}^{x}, \beta_{s}^{y}, \beta_{j}^{b}\right)^{T} \geq 0$ denotes the vector of scaling factors. The value of $\vec{D}(x, y, b ; g)$ under environmentally regulated technology can be calculated by solving the following DEA-type model:

$$
\begin{aligned}
\vec{D}^{r}(x, y, b ; g) & =\max w_{m}^{x} \beta_{m}^{x}+w_{s}^{y} \beta_{s}^{y}+w_{j}^{b} \beta_{j}^{b} \\
\text { s.t. } & \sum_{n=1}^{N} z_{n} x_{m n} \leq x_{m}-\beta_{m}^{x} g_{x m}, m=1, \ldots, M, \\
& \sum_{n=1}^{N} z_{n} y_{s n} \geq y_{s}+\beta_{s}^{y} g_{y s}, s=1, \ldots S, \\
& \sum_{n=1}^{N} z_{n} b_{j n}=b_{j}-\beta_{j}^{b} g_{b j}, j=1, \ldots J, \\
& z_{n} \geq 0, n=1,2, \ldots, N \\
& \beta_{m}^{x}, \beta_{s}^{y}, \beta_{j}^{b} \geq 0 .
\end{aligned}
$$

The directional vector $g$ can be set up in different ways, based on given policy goals. If $\vec{D}(x, y, b ; g)=0$, then the specific unit to be evaluated is located on the frontier of best practices in the direction of $g$. Carbon technical efficiency (CTE) is defined based on the non-radial DDF. Here, there are three inputs, one desirable output, and one undesirable output. We set the weight vector of $S, M$, and $J$ as one-third each for input, desirable output, and undesirable output respectively. We also set the directional vectors as $g=(-x, y,-b)$, based on Zhou et al. [9].

According to Zhang and Xie [23], the overall eco-friendly efficiency or CTE for industries is defined as the average efficiency of each factor. Suppose that $\beta_{x}^{*}, \beta_{y}^{*}$, and $\beta_{b}^{*}$ represent the optimal solutions to Equation (5), then the CTE can be formulated as:

$$
C T E=1-\frac{1}{M+S+J}\left(\sum_{m=1}^{M} \beta_{x m}^{*}+\sum_{s=1}^{S} \beta_{y s}^{*}+\sum_{j=1}^{J} \beta_{b j}^{*}\right)
$$

\subsection{The Shadow Price of Undesirable Output and the Morishima Elasticity of Substitution}

In this subsection, a dual DDF model is used to estimate the shadow prices of $\mathrm{CO}_{2}$ and the elasticity of substitution for input. The shadow cost function of a non-radial DDF may be defined as

$$
\begin{aligned}
& \min v x_{0}-u y_{0}+r b_{0} \\
& \text { s.t. } \\
& v x-u y+r b \geq 0 \forall n \\
& v \geq\left[\frac{1}{g_{1}^{x}}, \ldots, \frac{1}{g_{m}^{x}}, \ldots, \frac{1}{g_{M}^{x}}\right] \\
& u \geq\left[\frac{1}{g_{1}^{y}}, \ldots, \frac{1}{g_{s}^{y}}, \ldots, \frac{1}{g_{s}^{y}}\right] \\
& r \geq\left[\frac{1}{g_{1}^{b}}, \ldots, \frac{1}{g_{j}^{b}}, \ldots, \frac{1}{g_{j}^{b}}\right] .
\end{aligned}
$$


In Equation (6), $v \in R^{m}, u \in R^{s}$, and $r \in R^{j}$ are the dual-variable vectors of the input $\left(x \in R^{m}\right)$, the desirable output $\left(y \in R^{s}\right)$, and the undesirable output $\left(b \in R^{j}\right)$ respectively. The dual variables of the input, desirable output, and undesirable output can be estimated by the linear programming of Equation (6). The dual Equation (6) aims to minimize the virtual cost of the specific company concerned. In this regard, the dual DDF model is a type of product maximization model in which the virtual cost is at best zero (non-positive) when $\vec{D}(x, y, b ; g)=0$ for the DDF-efficient unit.

The dual variables $v \in R^{m}$ and $r \in R^{j}$ can be interpreted as the shadow prices of the input and undesirable output, respectively. $u \in R^{s}$ denotes the marginal virtual income of the desirable output. Assuming that the absolute shadow price of the undesirable output is equal to its market price $\left(p^{b}\right)$, the relative shadow price of the undesirable output with regard to the desirable output $\left(p^{y}\right)$ can be measured by

$$
r=u \times \frac{p^{b}}{p^{y}}
$$

In other words, the shadow price of the undesirable output can be interpreted as a marginal abatement cost that represents the marginal rate of transformation between undesirable and desirable output. Under the environmental regulations, the abatement of pollutants is not free but costly for companies because they incur an opportunity cost associated with reducing desirable output.

The curvature of the isoquant curve reflects the degree of substitutability of the input factors in the production function. Following Lee and Zhang [29], the elasticity of substitution between input $x_{i}$ and $x_{j}$ can be estimated by employing the idea of indirect Morishima elasticity of substitution, as shown in Equation (8). Morishima elasticity is defined as the shadow price ratio between the two factors [30]. As shown in Table 1, most research on Morishima elasticity is based on the distance function approach with input-orientation. This is because the substitution between traditional input, such as capital and labor, and energy input is crucial in order to find the potential of energy-saving efficiency enhancement through additional investment in energy-saving technologies. Based on the table, this paper analyzes the input elasticity of substitution among three types of input: capital, labor, and energy. It also examines the shadow price of the undesirable output of carbon emissions in accordance with the literature. In the simplest format, Morishima elasticity for input captures the degree to which the relative shadow prices of types of input should be altered to allow substitutability among such input along the isoquant curve. A high value for Morishima elasticity indicates low-level substitutability. It should be noted that $M_{i j} \neq M_{j i}$ because the ratios related to the two input shadow prices differ depending upon which input is used as the basis. The degree of substitution of $x_{j}$ for $x_{i}$ does not coincide with the substitution of $x_{i}$ for $x_{j}$ in general. Further, even if Morishima elasticity can be calculated for all three types of input and output perspective, we focus only on the elasticity between input and undesirable output. This is because we want to examine the potential of green technology investment for the sustainability of the ETS policies. It should also be noted that this application of Morishima elasticity is especially important in our research field of the capital-intensive petrochemical industry. Thus, it may provide useful insights with regard to the green investment promotion effect of the ETS policies. Hence,

$$
M_{i j}=\frac{v_{i}}{v_{j}}
$$


Table 1. Literature that considers Morishima elasticity.

\begin{tabular}{cccc}
\hline Researchers & Sector & Finding & Model \\
\hline Färe et al. [31] & Electric utilities & $\begin{array}{c}\text { Output elasticity of substitution } \\
\text { between electricity and sulfur } \\
\text { dioxide }\left(\mathrm{SO}_{2}\right) \text {, shadow price of } \mathrm{SO}_{2}\end{array}$ & Distance function \\
\hline Lee and Zhang [29] & Manufacturing industry & $\begin{array}{c}\text { Input elasticity of substitution } \\
\text { among energy and non-energy } \\
\text { shadow price of } \mathrm{CO}_{2}\end{array}$ & Distance function \\
\hline Lee and Jin [30] & $\begin{array}{c}\text { Electric power } \\
\text { generation industry }\end{array}$ & $\begin{array}{c}\text { Input elasticity of substitution } \\
\text { between thermal capital and nuclear } \\
\text { capital and their shadow prices }\end{array}$ & Distance function \\
\hline Zhang et al. [32] & Poyang Lake & $\begin{array}{c}\text { Input and output elasticity of } \\
\text { substitution, shadow price of carbon }\end{array}$ & measure (SBM) \\
DEA
\end{tabular}

\section{Characteristics of Data and Empirical Results}

\subsection{Data}

At the initial stage of the ETS, the Korean government selected 525 ETS member companies from all industrial fields, as shown in Table 2. These companies are substantial carbon emitters with more than 1.25 billion tons emitted per business, or 25,000 tons per factory site, as calculated from three-year averages of 2012 to 2014. During the initial ETS stage, from 2015 to 2017, all these companies are allowed $100 \%$ free permits. As long as the companies maintain carbon production at the same levels as the prior three years, they have no obligation to buy carbon allowance permits. However, because production volume increases every year, the companies must emit less carbon from the increased production processes. Since the free allowance permit is excessively generous at this initial stage, there has been no significant carbon trading. In the first year (2015), the volume of carbon trading was less than 1\%, and the average price was about US \$5 per carbon ton. The reason is that many ETS member companies are export-oriented; thus, they are concerned that because of the unilateral ETS burden, they may lose their price competitiveness. Such companies believe that the government should consider this issue; thus, the government has established an initial stage goal at a modest average of the BAU level. In order to avoid unexpected third-party manipulation, only ETS member companies can buy and sell the carbon allowance permits. However, in the second stage from 2018 to 2020, member companies will be allowed $97 \%$ of emissions targets free of charge; then, certified third parties can participate in carbon trading.

Table 2. The industries and the numbers of companies in the Korean ETS.

\begin{tabular}{cccc}
\hline Industry & Numbers & Industry & Numbers \\
\hline Construction & 40 & Textiles & 15 \\
Mining & 2 & Water & 3 \\
Machinery & 19 & Cement & 25 \\
Wood processing & 7 & Glass & 24 \\
Electronic, displays, and semiconductors & 45 & Food and drink & 23 \\
Power and energy & 38 & Car manufacturing & 24 \\
Nonmetallic & 24 & Oil refining & 4 \\
Petrochemical & 85 & Paper & 44 \\
Shipbuilding & 8 & Steel & 40 \\
Telecommunications & 6 & Waste & 44 \\
Aviation & 5 & Total & 525 \\
\hline
\end{tabular}


In order to examine this ETS policy, we collected data from 63 companies in the petrochemical industry in 2014. We chose the petrochemical industry because it is the main group in the ETS that has homogeneity. We used the data to evaluate CTE, the shadow prices of carbon emissions, and the substitutability of types of input by using Morishima elasticity.

With regard to the output variables, we selected sales turnover $(T)$ as a sole desirable output and carbon $(C)$ as an undesirable output. We also selected two basic types of input, labor $(L)$, and capital $(K)$, and added energy $(E)$ as the third input for environmental performance. The data for labor, capital, and turnover were derived from DART (the Data Analysis, Retrieval, and Transfer System) and Alio (Public Information Online). Energy and carbon data were taken from the Greenhouse Gas Inventory \& Research Center of Korea. The $\mathrm{CO}_{2}$ data was unavailable for the research period; thus, we interpolated the numeric values from the GHG emissions data, which includes other gases such as methane $\left(\mathrm{CH}_{4}\right)$, nitrogen $\left(\mathrm{N}_{2} \mathrm{O}\right)$, hydrofluorocarbons (HFCs), perfluorinated compounds (PFCs), and sulfur hexafluoride $\left(\mathrm{SF}_{6}\right)$. In general, studies on the energy and environment (E\&E) field have extracted pure $\mathrm{CO}_{2}$ values under the International Panel on Climate Change (IPCC) guidelines by using a macro type of data such as fuel $[13,23,33]$, consumption rate, and so on. However, we focus on the company level; and in Korea, only GHG data is available. Thus, we interpolate GHG data into a company's carbon value because carbon consists of $80 \%$ of GHG emissions worldwide, a percentage that according to the UNFCCC is the same in Korea. Because of the scarcity of some data, only 63 of 85 companies were included in the analysis. The basic data statistics for these companies are shown in Table 3.

Table 3. Descriptive statistics.

\begin{tabular}{ccccccc}
\hline Variable & Type & Unit & Mean & Std. Dev. & Max. & Min. \\
\hline Sales turnover & Desirable output & US \$ Billion & $2,102,894$ & $3,800,331$ & $18,076,229$ & 59,824 \\
Carbon & Undesirable output & $\mathrm{CO}_{2}$ equivalent tons & $756,249.6$ & $1,436,648$ & $7,063,768$ & 23,461 \\
Capital & Input & US \$ Billion & 110,867 & 195,610 & $1,125,781$ & 3666 \\
Labor & Input & Per person & 1236.742 & 2198.649 & 2669 & 57 \\
Energy & Input & Terajoules (TJ) & $13,438.59$ & $2,626,7.12$ & 134,604 & 356 \\
\hline
\end{tabular}

Sources: Greenhouse Gas Inventory \& Research Center of Korea (http://www.gir.go.kr/) [34]. DART: Data Analysis, Retrieval, and Transfer System (http://dart.fss.or.kr/) [35]. Alio: Public Information Online (http://www.alio.go.kr/) [36].

Table 4 presents the input and output correlation matrix. The results show that the correlation between the types of input and output is positive. Capital and labor are significantly related with desirable output, and energy influences carbon significantly. Thus, an overall increase in input causes an increase in output, which strongly suggests that our approach is feasible for an empirical study.

Table 4. Input and output correlation matrix.

\begin{tabular}{cccccc}
\hline Variable & Capital & Labor & Energy & Turnover & Carbon \\
\hline Capital & 1 & & & & \\
Labor & 0.900 & 1 & & & \\
Energy & 0.565 & 0.424 & 1 & & \\
Turnover & 0.913 & 0.837 & 0.491 & 1 & \\
Carbon & 0.554 & 0.410 & 0.984 & 0.478 & 1 \\
\hline
\end{tabular}

\subsection{CTE and the Shadow Price of Carbon}

Based on Equations (4) and (5), CTE is calculated in Table 5. The CTE scores range from 0.094 to 1 and the average CTE score is approximately $47.2 \%$. The latter result implies that it is possible to accomplish a $52.8 \%$ efficiency enhancement in the petrochemical industry when it operates on the frontier of environmental production technology. Of the ETS group, 12.7\% (eight companies) exhibit best practice in CTE, while a further eight companies have CTE levels that are lower than $20 \%$. 
This result implies that there is a strong tendency for bipolarization among the leading companies in Korea; thus, the government should take measures to support (or regulate more strictly) those companies with low CTE scores in order to improve their efficiency. Since there is a potential of more than $50 \%$ to improve eco-friendly efficiency, more proactive regulation is urgently needed for companies with lower CTE levels to encourage them to make greater efforts to enhance such levels.

Table 5. Carbon technical efficiency and the shadow prices of carbon emissions.

\begin{tabular}{|c|c|c|c|c|c|}
\hline DMU & Efficiency & Shadow Prices & DMU & Efficiency & Shadow Prices \\
\hline DMU1 & 0.240 & 40.56 & DMU33 & 0.203 & 15.20 \\
\hline DMU2 & 0.704 & 57.66 & DMU34 & 1.000 & 8.94 \\
\hline DMU3 & 0.108 & 0.71 & DMU35 & 0.371 & 5.67 \\
\hline DMU4 & 0.903 & 14.80 & DMU36 & 0.226 & 2.71 \\
\hline DMU5 & 0.548 & 0.24 & DMU37 & 0.351 & 11.20 \\
\hline DMU6 & 0.157 & 19.45 & DMU38 & 0.223 & 38.77 \\
\hline DMU7 & 0.233 & 73.15 & DMU39 & 0.581 & 8.92 \\
\hline DMU8 & 0.147 & 28.22 & DMU40 & 1.000 & 24.11 \\
\hline DMU9 & 0.217 & 43.93 & DMU41 & 0.276 & 7.20 \\
\hline DMU10 & 0.199 & 37.18 & DMU42 & 0.608 & 0.24 \\
\hline DMU11 & 1.000 & 53.37 & DMU43 & 0.353 & 73.46 \\
\hline DMU12 & 0.273 & 27.42 & DMU44 & 0.251 & 69.85 \\
\hline DMU13 & 0.505 & 45.66 & DMU45 & 0.232 & 17.37 \\
\hline DMU14 & 0.395 & 18.30 & DMU46 & 0.537 & 24.27 \\
\hline DMU15 & 0.195 & 2.09 & DMU47 & 0.618 & 6.09 \\
\hline DMU16 & 0.255 & 3.05 & DMU48 & 0.260 & 53.55 \\
\hline DMU17 & 0.435 & 13.12 & DMU49 & 0.231 & 29.40 \\
\hline DMU18 & 1.000 & 0.57 & DMU50 & 0.094 & 4.37 \\
\hline DMU19 & 0.243 & 4.48 & DMU51 & 0.547 & 2.86 \\
\hline DMU20 & 0.701 & 23.89 & DMU52 & 1.000 & 15.12 \\
\hline DMU21 & 0.723 & 7.23 & DMU53 & 0.107 & 0.48 \\
\hline DMU22 & 0.460 & 2.78 & DMU54 & 0.361 & 1.64 \\
\hline DMU23 & 0.283 & 18.72 & DMU55 & 0.480 & 22.09 \\
\hline DMU24 & 0.337 & 13.80 & DMU56 & 1.000 & 6.32 \\
\hline DMU25 & 0.409 & 3.66 & DMU57 & 0.294 & 8.93 \\
\hline DMU26 & 1.000 & 18.19 & DMU58 & 0.650 & 3.62 \\
\hline DMU27 & 0.438 & 0.10 & DMU59 & 0.175 & 1.10 \\
\hline DMU28 & 1.000 & 2.60 & DMU60 & 0.223 & 23.80 \\
\hline DMU29 & 0.196 & 1.19 & DMU61 & 0.855 & 2.14 \\
\hline DMU30 & 0.450 & 4.52 & DMU62 & 1.000 & 0.51 \\
\hline DMU31 & 0.348 & 12.81 & DMU63 & 1.000 & 2.89 \\
\hline DMU32 & 0.555 & 1.59 & Average & 0.472 & 17.27 \\
\hline
\end{tabular}

Table 5 also shows another shadow price result. The concept of the shadow price is widely used to measure the abatement cost caused by environmental regulations [29,32]. The shadow price not only presents an estimated value of the opportunity cost for undesirable output but also provides such output with meaningful guidelines to formulate regulatory policies for public decision-makers. In this study, the shadow price is equal to the carbon price for each unit of carbon emissions abatement.

The calculated average shadow price of all 63 companies is US \$17.27. This result is far from the real value of US $\$ 10$ at the end of 2014 . In other words, the market price reflected just $58 \%$ of the shadow price. This situation indicates that the carbon price in the ETS market is too low to encourage companies to participate actively in the market. The small trading volume supports the hypothesis that the low carbon price prevents the ETS from being proactively pursued. As shown in Figure 1, the market price of carbon emissions remained at approximately US \$10 dollars for almost a year and then began to rise, increasing to US \$18 when each company had to register its carbon emissions performance at the end of March, 2016. This trend implies that companies do not regard carbon emissions regulation seriously; thus, they do not have a strong motivation to invest in 
energy-saving technologies or less energy-intensive production processes. Indeed, the market price only increased, almost doubling from its initial price, when each company had to register its carbon emissions performance. An ETS member company could and should buy a carbon emissions permit at the doubled price, otherwise it should pay triple the price as a penalty for its unfulfilled carbon emissions target. Moreover, most companies did not participate in carbon trading because of the $100 \%$ free allowance; thus, the market price could not accurately reflect the willingness of companies to engage in the additional abatement of carbon emissions.

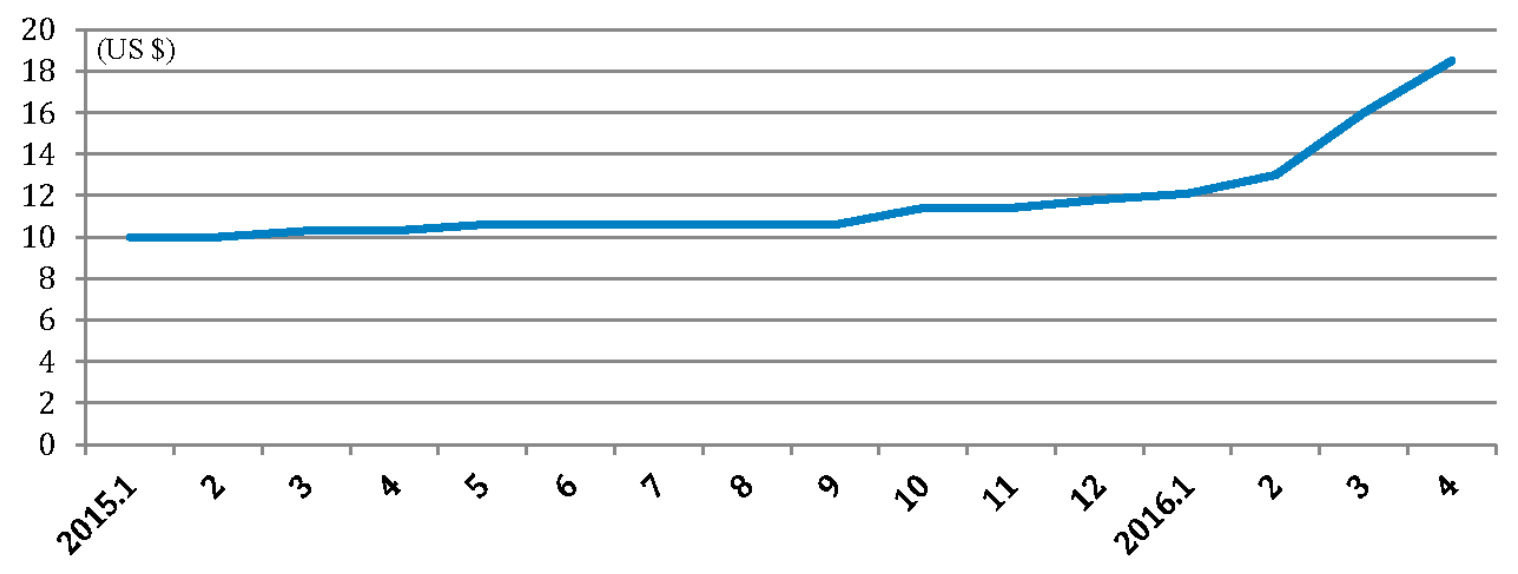

Figure 1. Market price trend of the carbon emissions allowance under the ETS.

\subsection{Morishima Elasticity of Substitution}

As shown by the CTE results, the Korean government should regulate the ETS more proactively because most companies show a very lower level of eco-friendly efficiency. Moreover, the market price for the carbon emissions allowance is much lower than its shadow price. This difference implies that even if a significant gap exists between the market price and the shadow price of carbon emissions, companies are not very willing to enhance their CTE and proactively participate in carbon trading. So that these companies take strategic decisions about investment in energy-saving green technology more seriously, capital-intensive enhancement of CTE performance should be more feasible. In order to evaluate the feasibility of green investment, we examine input/output-oriented Morishima elasticity. Table 6 presents the results of the Morishima elasticity of substitution that we employ to evaluate the sustainability of ETS policies for green investment promotion. The figures are calculated from Equation (8) and evaluated based on the shadow price ratio of inputs. As shown in Table 6, $\mathrm{M}_{k l}$ is 2252.9 , which is much higher than an $\mathrm{M}_{l k}$ of zero. It should be noted that a higher Morishima value implies lower substitutability. The findings indicate that there is no difficulty in capital substituting for labor, although labor cannot substitute for capital. Such a result is to be expected in the capital-intensive petrochemical industry.

Table 6. Morishima-type elasticities of substitution (input).

\begin{tabular}{cc}
\hline Elasticity of Substitution & Estimate \\
\hline $\mathrm{M}_{k l}$ & 2252.9 \\
$\mathrm{M}_{l k}$ & 0 \\
$\mathrm{M}_{k e}$ & 33.70317 \\
$\mathrm{M}_{e k}$ & 0 \\
$\mathrm{M}_{l e}$ & 0.34207 \\
$\mathrm{M}_{e l}$ & 52.17643 \\
\hline
\end{tabular}

In addition, $\mathrm{M}_{k e}$ is 33.7 , implying that capital can easily be substituted by energy. Thus, it is strongly recommended that energy-intensive companies should expand their investment in facilities 
and energy-saving technology. Finally, $\mathrm{M}_{e l}$ is higher than $\mathrm{M}_{l e}$, which means that energy can be substituted by labor but not vice versa. Hence, the results show that in a capital-intensive industry, labor is easily substituted with energy; thus, green technology also leads to labor-saving operations.

\section{Conclusions}

One year has passed since the Korean government inaugurated its ETS in 2015; consequently, it may be too early to evaluate the sustainability of the government's ETS policies. Although there have been problems such as a low volume of carbon trading and unduly low semi-fixed prices, such policies must continue successfully. The reason is that ETS policies are necessary for optimal control of future challenges and for a low carbon society, both of which are goals that the Korean government should pursue because the achievement of low carbon emissions is an engine for future development. From the beginning, there have been excessive claims and opposition from diverse interest groups such as politicians, industrial leaders, business managers, and experts. Because of the complaints from these people, the government has set its carbon-reduction targets at much lower levels than originally planned, resulting in a lack of governance for sustainable performance. In this research, we examined three governance factors of sustainability with regard to Korean ETS policies.

First, the eco-friendly efficiency of CTE shows that companies have significant potential to enhance their efficiency. The average CTE for the 63 ETS member companies in our sample was 0.472 . This figure suggests that there is potential for a $52.8 \%$ enhancement of such companies' CTE. In other words, the proactive participation of companies in the ETS should lead to an efficiency improvement that more than doubles the current average. If such companies can obtain information about the best practices of companies on the frontier, they can certainly improve their CTE. Moreover, in order to avoid bipolarization of carbon-reduction performance, the government should make cross-learning from best practices easier and more profitable for the ETS member companies.

Based on this empirical result, we examined the second governance factor of market price appropriateness. Using the shadow price of carbon emissions, the empirical result showed that the market price was approximately half that of the shadow price for almost a year. This result implies that an excessively regulated market price prevents companies from proactively participating in carbon trading. Further, it is clear that there is a missing link in the carbon trading policy of the ETS. In order to find this missing link, we used a third stage of empirical testing in terms of Morishima elasticity between the input and undesirable output of carbon emissions. The findings showed that there is significantly high substitutability between capital and energy input, implying that greater investment in green technology results in higher levels of energy-saving efficiency. This improvement is the ultimate goal of the Korean government's ETS policies. However, unfortunately, the current severely distorted restriction of unduly generous carbon emissions targets has resulted in poor performance from efficiency and shadow price perspectives. Thus, the empirical results strongly suggest that the Korean government should encourage the ETS member companies to make greater efforts to decrease their carbon emissions. Such encouragement should not rely on a voluntary approach but should be in the form of a stricter regulated system with much lower free allowances for carbon emissions. In particular, CTE is bipolarized, implying that there is significant potential for companies with low CTE to improve easily and effectively. Such improvements can originate from intra-industry technological transfers or the learning effects of best practice taken from those companies on the frontier of the DDF production possibility curve.

This research used duality theory with a non-radial, non-parametric DDF approach to examine diverse production characteristics from the sustainable development perspective. Using input-oriented DDF, CTE was measured in the first stage. Further, by using the dual model of non-radial DDFs, we obtained the shadow prices of carbon emissions and input substitutability. Because the methodology could not reflect the dynamic effect of the ETS, it may have limited implications. Moreover, the empirical test was undertaken in the petrochemical industry only. Thus, even if the research provides clearer insights because of the homogeneity of the DMUs, it still needs to expand 
its empirical base to encompass diverse industries by using the meta-frontier approach. All the data in the paper is based on the one year of 2015, and it may be too short to infer the significant implications and suggestions. However, since the Korean government initiated the target management system (TMS) five years before ETS, all the covered companies are ready to participate in the ETS and their efforts are relevant to be analyzed even in the short term. Of course, our research need to be complemented with the dynamic changes of the policy effects over time for the future research issue.

Are emissions trading policies sustainable in Korea? This paper showed clearly the lack of governance for a sustainable ETS policy in Korea; thus, the Korean government should engage in greater proactive efforts to upgrade the future sustainable performance of the ETS [37]. Especially, for the sustainable performance of ETS, the covered companies should make efforts to invest in green technology to improve its environmental efficiency, and the paper showed that there is huge potential for benefits from green investment to enhance environmental efficiency. However, the government should support for the companies to invest on the green technology as early as possible to fill the missing link between the target and the current huge lack of the environmental efficiency.

Acknowledgments: This work was supported by Inha University Research Grant.

Author Contributions: The authors contributed equally to this work.

Conflicts of Interest: The authors declare that there are no conflicts of interest.

\section{References}

1. Zhang, N.; Choi, Y. A note on the evolution of directional distance function and its development in energy and environmental studies 1997-2013. Renew. Sustain. Energy Rev. 2014, 33, 50-59. [CrossRef]

2. Shephard, R.W. Theory of Cost and Production Functions; Princeton University Press: Princeton, NJ, USA, 1970.

3. Chambers, R.; Chung, Y.; Färe, R. Benefit and distance functions. J. Econ. Theory 1996, 70, 407-419. [CrossRef]

4. Chung, Y. Directional Distance Functions and Undesirable Outputs. Ph.D. Thesis, Southern Illinois University, Carbondale, IL, USA, 1996.

5. Kaneko, S.; Fujii, H.; Sawazu, N.; Fujikura, R. Financial allocation strategy for the regional pollution abatement cost of reducing sulfur dioxide emissions in the thermal power sector in China. Energy Policy 2010, 38, 2131-2141. [CrossRef]

6. Fukuyama, H.; Weber, W. A directional slacks-based measure of technical efficiency. Socio-Econ. Plan. Sci. 2009, 43, 274-287. [CrossRef]

7. Zhou, P.; Poh, K.L.; Ang, B.W. A non-radial DEA approach to measuring environmental performance. Eur. J. Oper. Res. 2007, 178, 1-9. [CrossRef]

8. Chang, T.; Hu, J.L. Total-factor energy productivity growth, technical progress, and efficiency change: An empirical study of China. Appl. Energy 2010, 87, 3262-3270. [CrossRef]

9. Zhou, P.; Ang, B.W.; Wang, H. Energy and $\mathrm{CO}_{2}$ emission performance in electricity generation: A non-radial directional distance function approach. Eur. J. Oper. Res. 2012, 221, 625-635. [CrossRef]

10. Wang, K.; Wei, Y.M.; Zhang, X. Energy and emissions efficiency patterns of Chinese regions: A multi-directional efficiency analysis. Appl. Energy 2013, 104, 105-116. [CrossRef]

11. Barros, C.P.; Managi, S.; Matousek, R. The technical efficiency of the Japanese banks: Non-radial directional performance measurement with undesirable outputs. Omega 2012, 40, 1-8. [CrossRef]

12. Färe, R.; Grosskopf, S.; Pasurka, C.A., Jr. Environmental production functions and environmental directional distance functions. Energy 2007, 32, 1055-1066. [CrossRef]

13. Zhang, N.; Zhou, P.; Choi, Y. Energy efficiency, $\mathrm{CO}_{2}$ emission performance and technology gaps in fossil fuel electricity generation in Korea: A meta-frontier non-radial directional distance function analysis. Energy Policy 2013, 56, 653-662. [CrossRef]

14. Barros, C.P.; Peypoch, N. Technical efficiency of thermoelectric power plants. Energy Econ. 2008, 30, 3118-3127. [CrossRef]

15. Liu, C.H.; Lin, S.J.; Lewis, C. Evaluation of thermal power plant operational performance in Taiwan by data envelopment analysis. Energy Policy 2010, 38, 1049-1058. [CrossRef] 
16. Jaraite, J.; Maria, C.D. Efficiency, productivity and environmental policy: A case study of power generation in the EU. Energy Econ. 2012, 34, 1557-1568. [CrossRef]

17. Smyth, R.; Marayan, P.; Shi, H. Substitution between energy and classical factor inputs in the Chinese steel sector. Appl. Energy 2011, 88, 361-367. [CrossRef]

18. Wei, Y.M.; Liao, H.; Fan, Y. An Empirical Analysis of Energy Efficiency in China's Iron and Steel Sector. Energy 2007, 32, 2262-2270. [CrossRef]

19. He, F.; Zhang, Q.; Lei, J.; Fu, W.; Xu, X. Energy efficiency and productivity change of China's iron and steel industry: Accounting for undesirable outputs. Energy Policy 2013, 54, 204-213. [CrossRef]

20. Matsushita, K.; Yamane, F. Pollution from the electric power sector in Japan and efficient pollution reduction. Energy Econ. 2012, 34, 1124-1130. [CrossRef]

21. Kumar, S.; Managi, S. Sulfur dioxide allowances: Trading and technological progress. Ecol. Econ. 2010, 69, 623-631. [CrossRef]

22. Sueyoshi, T.; Goto, M. Efficiency-based rank assessment for electric power industry: A combined use of data envelopment analysis (DEA) and DEA-discriminant analysis (DA). Energy Econ. 2012, 34, 634-644. [CrossRef]

23. Zhang, N.; Xie, H. Toward green IT: Modeling sustainable production characteristics for Chinese electronic information industry, 1980-2012. Technol. Forecast. Soc. Chang. 2015, 96, 62-70. [CrossRef]

24. Picazo-Tadeo, A.J.; Reig-Martínez, E.; Hernández-Sancho, F. Directional distance functions and environmental regulation. Resour. Energy Econ. 2005, 27, 131-142. [CrossRef]

25. Mandal, S.K.; Madheswaran, S. Environmental efficiency of the Indian cement industry: An interstate analysis. Energy Policy 2010, 38, 1108-1118. [CrossRef]

26. Martini, G.; Manello, A.; Scotti, D. The influence of fleet mix, ownership and LCCs on airports' technical/environmental efficiency. Transp. Res. E 2013, 50, 37-52. [CrossRef]

27. Oestreich, A.M.; Tsiakas, I. Carbon Emissions and Stock Returns: Evidence from the EU Emissions Trading Scheme. J. Bank. Financ. 2015, 58, 294-308. [CrossRef]

28. Färe, R.; Grosskopf, S.; Lovell, C.A.K. Multilateral productivity comparisons when some outputs are undesirable: A non parametric approach. Rev. Econ. Stat. 1989, 71, 90-98. [CrossRef]

29. Lee, M.; Zhang, N. Technical efficiency. Shadow price of carbon dioxide emissions, and substitutability for energy in the Chinese manufacturing industries. Energy Econ. 2012, 34, 1492-1497. [CrossRef]

30. Lee, M.; Jin, Y. The substitutability of nuclear capital for thermal capital and the shadow price in the Korean electric power industry. Energy Policy 2012, 51, 834-841. [CrossRef]

31. Färe, R.; Grosskopf, S.; Noh, D.; Weber, W. Characteristics of a polluting technology: Theory and practice. J. Econom. 2005, 126, 469-492. [CrossRef]

32. Zhang, N.; Kong, F.; Kung, C. On modeling environmental production characteristics: A slack -based measure for China's Poyang lake ecological economics zone. Comput. Econ. 2015, 46, 389-404. [CrossRef]

33. Wei, C.; Loschel, A.; Liu, B. An empirical analysis of the $\mathrm{CO}_{2}$ shadow price in Chinese thermal power enterprises. Energy Econ. 2013, 40, 22-31. [CrossRef]

34. Greenhouse Gas Inventory \& Research Center of Korea. Available online: http://www.gir.go.kr/ (accessed on 15 December 2015).

35. DART: Data Analysis, Retrieval and Transfer Syste. Available online: http://dart.fss.or.kr/ (accessed on 15 December 2015).

36. Alio: All Public Information in Online. Available online: http://www.alio.go.kr/ (accessed on 15 December 2015).

37. Choi, Y. Intermediary Propositions for Green Growth with Sustainable Governance. Sustainability 2015, 7, 14785-14801. [CrossRef]

(C) 2016 by the authors; licensee MDPI, Basel, Switzerland. This article is an open access article distributed under the terms and conditions of the Creative Commons Attribution (CC-BY) license (http:/ / creativecommons.org/licenses/by/4.0/). 